\title{
Analysis of the Causes of Cracks in the Bottom Floor of the Underground Garage of the Hefei Government Affairs Center by using 3D Finite-Element Analysis
}

\author{
ZHU Lei ${ }^{1, *}$, PENG Jianhe ${ }^{2}$ and REN Quhong ${ }^{3}$ \\ ${ }^{1}$ Department of Civil Engineering, Hefei University, Hefei 230022, China \\ ${ }^{2}$ Anhui and Huaihe River Water Resources Research Institute, Hefei 230099, China \\ ${ }^{3}$ Engineering Science Center of REENER Compan, C.U. 15100, Aalto, Finland
}

Received 8 April 2015; Accepted 13 September 2015

\begin{abstract}
A three-dimensional finite-element software program is used in this study to analyze the causes of cracks in an underground garage. Numerous cracks, serious and regular alike, can be found in the underground garage of the Hefei Government Affairs Center. These cracks are mainly located around the central part of the bottom floor within a 44.6$57.8 \mathrm{~m}$ radius. To explore the causes of the cracks, two attempts are made. On one hand, on-site crack detection and underground water monitoring are conducted. On the other hand, the finite-element software program ANSYS is adopted to establish a finite-element model for the floor-foundation and connecting beam-foundation soil systems of the underground garage. Furthermore, the influences of the underground foundation, underground water level, soil expansion, and Poisson ratio on the bottom floor are calculated and analyzed. On the basis of the calculation and monitoring results, the following conclusion can be made: underground water is the main cause of the bottom floor cracks because underground water exerts a pushing force from the bottom and causes the expansibility of expansive soil. The study aims to provide a theoretical basis for the treatment of cracking in the Hefei Government Affairs Center, and offer a reference for the design, construction, and maintenance of similar projects.
\end{abstract}

Keywords: Underground Garage, ANSYS, Cracking, Foundation Settlement, Underground Water, Expansive Soil

\section{Introduction}

Given the continuous development of modern cities and building technology and the significant increase in urban spaces, an increasing number of high rise buildings are being constructed with one story or multistory basements, which are widely used as underground garages and underground shopping malls. However, owing to the considerably short period allotted for the field investigation, design cycle, and construction of such projects, these basements encounter serious cracking and leakage, which affect normal running and use. Thus, research on the cracks of underground garages has significant application value. Serious and regular cracks can be seen on the bottom floor of the underground garage of the Hefei Government Affairs Center. These cracks are mainly located around the central part of the bottom floor within a 44.6-57.8 m radius. To explore the causes of the cracks and strengthen the bottom floor, this study mainly focuses on the following aspects: field detection and numerical calculation. First, on-site crack detection and underground water monitoring are conducted. Second, according to the detection and monitoring results, the 3D finite-element software program ANSYS is adopted to establish a finite-element model for the floor-foundation and connecting beam-foundation soil systems of the underground garage. This program calculates and analyzes the influences of changes in underground foundation, underground water level, soil expansion, and Poisson ratio

* E-mail address: zhuleianhui@163.com ISSN: 1791-2377 @ 2015 Kavala Institute of Technology. All rights reserved. on the bottom floor. The stresses, strains, and displacement responses caused by the interaction of different loads are obtained. On the basis of the calculation and monitoring results, the following conclusion can be drawn: underground water is the main cause of the cracks in the bottom floor because underground water exerts a pushing force from the bottom and causes the expansibility of expansive soil.

The capability of the 3D finite-element software ANSYS to explore the causes of the cracks is proved to be reliable. This study aims to provide a theoretical basis for the treatment of cracks in the Hefei Government Affairs Center and serve as a reference for the design, construction, and maintenance of similar projects.

\section{Description of the problem}

The main building of the Hefei Government Affairs Center is a twin-tower building with 32 floors above ground. The skirt building has a frame structure with 4-6 floors. The total building area of the Hefei Government Affairs Center is $106957.58 \mathrm{~m}^{2}$. The skirt building in District 2 is $20 \mathrm{~m}$ high (4 floors in total: 1 floor below ground and 3 floors above ground). The building has a frame structure, and under the column is an independent foundation with a depth of 5.5-7.5 $\mathrm{m}$. The first underground floor is a garage with an area of $1300 \mathrm{~m}^{2}$.

The geomorphic units in the engineering site are hills and ditches mainly containing late Quaternary (Q3) clay. The part above the ditches is a $28 \mathrm{~m}$-thick powder clay layer with deposits from a few years ago. The strong-weathered zone of the bedrock is approximately $7 \mathrm{~m}$ thick. The engineering site 
was a farmland with a fish pond, soft soil, and rich underground water. From top to bottom, the soil layers are as follows: (1) miscellaneous fill, (2) powder clay, and (3) clay. The clay is expansive soil.

Serious cracks appear on the bottom floor of the garage in the skirt building of District 2 during usage. The garage is basically round, and the foundation beams under the bottom floor are mainly composed of an independent foundation and beams below the column. The bottom floor is $300 \mathrm{~mm}$ thick but becomes $400 \mathrm{~mm}$ thick when the radius is more than $57.8 \mathrm{~m}$. The structural layout of the bottom floor, foundation, and beams is shown in Fig. 1.

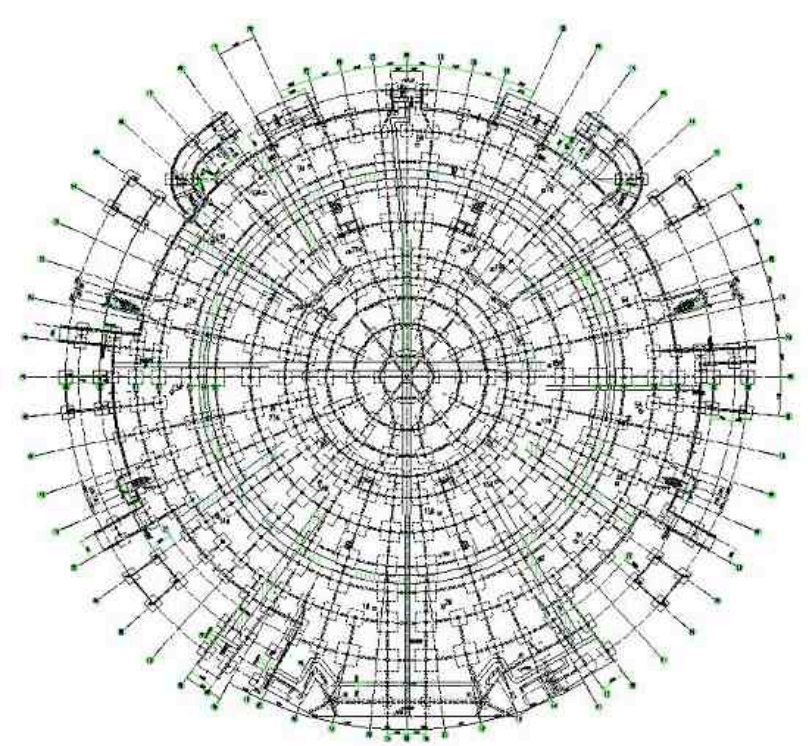

Fig. 1. Structural layout of the bottom floor, foundation, and beams

Serious and regular cracks appear in the bottom floor of the underground garage of the Hefei Government Affairs Center. Furthermore, cracks are found to frequent in the leveling blanket, particularly in the radius between 44.6 and $57.8 \mathrm{~m}$. The cracks are commonly ringed and radical, and most of which lie in the central part of the bottom floor. The widths of most of the cracks range from $0.05 \mathrm{~mm}$ to $0.2 \mathrm{~mm}$. Fig. 2 shows the distribution map of the cracks in the bottom floor.

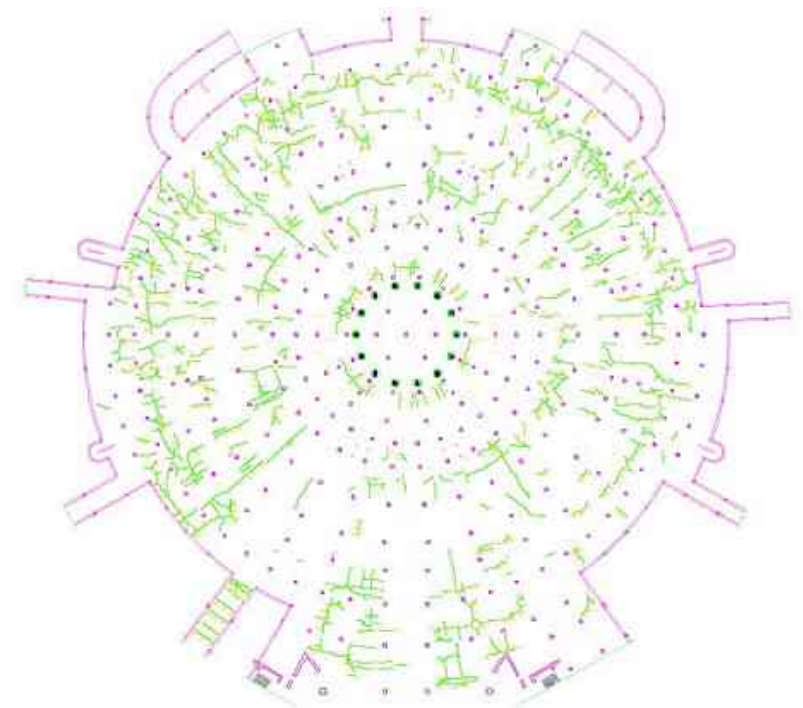

Fig. 2. Distribution map of the cracks in the bottom floor
On the basis of the measurement of the cracks in the core samples, cracks are found to be wide up and narrow down. Among the 14 core samples, 6 cracks are in the sloping blanket and 8 extend to the structural layer. The cracks in the structural layer are less than $0.05 \mathrm{~mm}$ wide.

\section{State of the art}

At present, numerical methods such as the finite-element method and finite-difference method, which can handle complicated boundaries and solve highly nonlinear problems, have been widely applied in the analysis of concrete cracks. ANSYS, which is a general finite-element computer program for the solution of structural and heat transfer engineering analyses, is widely used in various fields [1], [2], [3], [4], [5], [6]. Rough set theory was previously applied, and the approach of extracting the main cause of the crack was proposed for a hydraulic concrete structure. Water level and temperature were found to be the main influencers in dam construction [7]. ANSYS was applied to the static calculation for the workshop structure of a power station. The stress and displacement responses of concrete members in the engine floor were obtained, and the causes of cracks in the engine floor were determined and analyzed [8]. Computer simulation and traditional theoretical approaches were applied to calculate the bearing capacity of different cases. These approaches show that the ring walls above ground elevation were found to face the lateral pressure induced by the internal sand, which may lead to cracking [9]. According to the requirements of dam reinforcement engineering, the process of arch dam gradual loading and synchronous water level increase is simulated by using a 3D finite-element calculation model. The stress under the conditions of normal storage and temperature drop of the dam is calculated and analyzed, and a material parameter sensitivity analysis on dam foundation is conducted by using a variety of scenarios to comprehensively study the causes of cracks in the arch dams [10]. An extended finite-element method for the numerical simulation of the crack propagation process in concrete structures is adopted to simulate the nonlinear fracture behavior of concrete [11]. Three-dimensional finite-element simulation and nonlinear cracking analysis are implemented to analyze the causes of cracks and their propagation trends. The cracks are found to be the result of both accumulated temperature stress during construction and temperature sudden drop [12]. On the basis of the experiment observations, a model for the conductivity of cracked concrete is developed. This model can be used for the coupled transient finite-element analysis of a concrete dam subjected to an earthquake [13]. By combining reinforced concrete bond-slip theory with the nonlinear simulation capabilities of ANSYS, a practical calculation method for concrete crack width is developed; the results are compared with the experiment results [14]. Thus, a finite-element method can be applied to the calculation and analysis of the causes of concrete cracks. Although the studies on the causes of concrete cracks are numerous, they mainly focus on the influences of water level, temperature, and earthquake on ground concrete. However, the influences of changes in underground foundation, underground water level, soil expansion, and Poisson ratio on underground floors have not yet been calculated or analyzed by using a finite-element method. Thus, this study is conducted to fill in such a research gap. 


\section{Methodology}

\subsection{Structure detection}

(1) The size of the cross section of the detected frame beams can satisfy the design requirements. The quality is good in appearance with no open defects, such as bare bars, surface voids, or holes.

(2) The inferred strength value of the concrete in the basement ranges from $35.6 \mathrm{MPa}$ to $44.5 \mathrm{MPa}$, which satisfies the requirement of design strength level C35. The inferred strength value of the concrete in the first floor is within $31.5 \mathrm{MPa}$ to $45.4 \mathrm{MPa}$, which meets the requirement of design strength $\mathrm{C} 30$.

(3) The main bar configurations of the basement columns and frame beams all meet the design requirements. The stirrup configurations in the fine mesh region and normal region meet the design requirements.

\subsection{Groundwater level monitoring}

(1) On the basis of site investigations, three water-level monitoring holes (hole 1, hole 2, and hole 3) are constructed outside the garage. Throughout the rainy season, the water levels in holes 1,2 , and 3 were $3.38-4.15 \mathrm{~m}, 3.62-4.06 \mathrm{~m}$, and $2.81-3.78 \mathrm{~m}$ higher than the bottom floor, respectively. The monitoring results show the relation of underground water level to surface water.
(2) In the cracking area, a representative frame column and the bottom floor are selected for settlement observation. No obvious settlement occurs in the selected frame column and bottom floor, thus indicating settlement stability. The deformation of the bottom floor with the changes in underground water level is not obvious.

\subsection{Establishment of a finite-element analysis model}

According to the results of engineering quality detection, further analysis on the causes of the cracks is necessary. ANSYS is applied to calculate and analyze the bottom floor-foundation and beam-soil body structure systems [15]. Proper elements are selected to establish a 3D model. Factors such as foundation settlement, water head pressure, Poisson ratio, expansion ratio, and expansive soil thickness are considered. Under different engineering conditions, the different stress and strain states of the structure system are analyzed and the causes of cracks in the bottom floor are explored.

\subsubsection{Calculation parameters}

The physical and mechanical parameters of the materials of the bottom floor, foundation, beams, and bottom soil are listed in Table 1.

Table 1. Physical and mechanical parameters of materials

\begin{tabular}{ccccc}
\hline Material & Bulk density $\left(\mathrm{KN} / \mathbf{m}^{\mathbf{3}}\right)$ & Elastic modulus (MPa) & Poisson ratio & Tensile strength (MPa) \\
\hline Concrete & 23 & 31500 & 0.27 & 1.57 \\
Clay & 19.5 & 17.5 & $0.2-0.35$ & - \\
\hline
\end{tabular}

The partial coefficient is not considered in the load. The tensile stress is positive, whereas the compressive stress is negative. The Cartesian coordinate system of the right-hand rule is adopted. $\mathrm{X}$ and $\mathrm{Y}$ are the horizontal axes, whereas $\mathrm{Z}$ is the vertical axis.

\subsubsection{Calculation conditions]}

(1) Foundation settlement

(2) Underground water: The head pressures for the 1, 2, 3, 4 , and $5 \mathrm{~m}$ levels are calculated.

(3) The following expansion ratios, soil thicknesses, and Poisson ratios are taken into account: a) volume expansion ratios are $1 \%, 1.5 \%$, and $3 \% ; b)$ the expansive soil thicknesses of the clay layer are 1.5, 3, and 5; c) the Poisson ratios of the clay are $0.35,0.3,0.25$, and 0.2 .

\subsubsection{Model explanation}

A 3D 4-node tetrahedron element is adopted for the bottom floors, foundation, beams, and soil. A 3-direction restraint is used for the clay bottom and a horizontal restraint is established for the boundaries. The finite-element model is shown in Fig. 3. The whole model has 1037352 elements.

\section{Analysis results}

\subsection{Influence of foundation settlement}

Foundation settlement occurs when the upper structure exerts a load and leads to bottom floor settlement and pressure on the soil foundation. The upper structure load is converted to $150 \mathrm{kN} / \mathrm{m} 2$ on the foundation top. A three- direction restraint and a horizontal restraint are used on the clay bottom and clay boundaries, respectively.

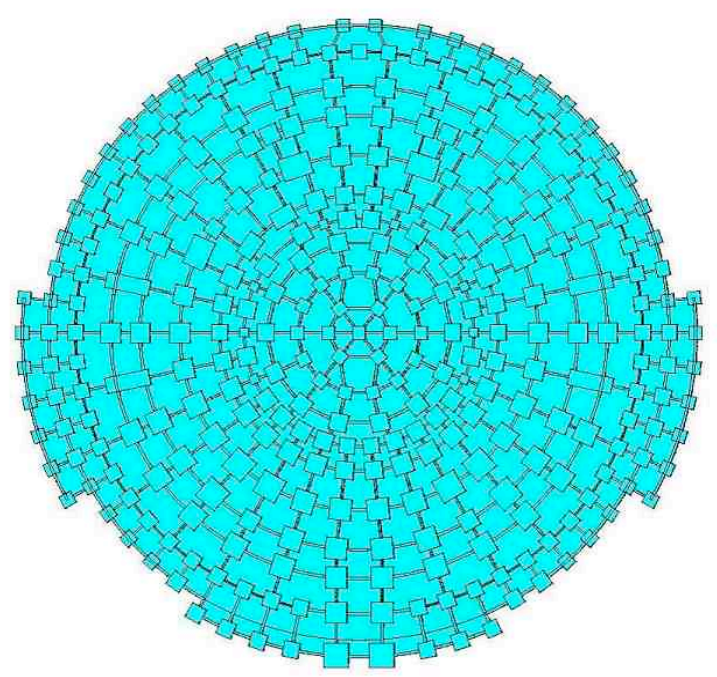

Fig. 3. Structural model of the bottom floor, foundation, and foundation beam

Fig. 4 shows the distribution of the first principal stress in the bottom floor when the foundation settles. The maximum first principal stress is approximately 0.6 $\mathrm{MPa}$. Most of the principal stress values are within the range of $0.35-0.55$ $\mathrm{MPa}$. 


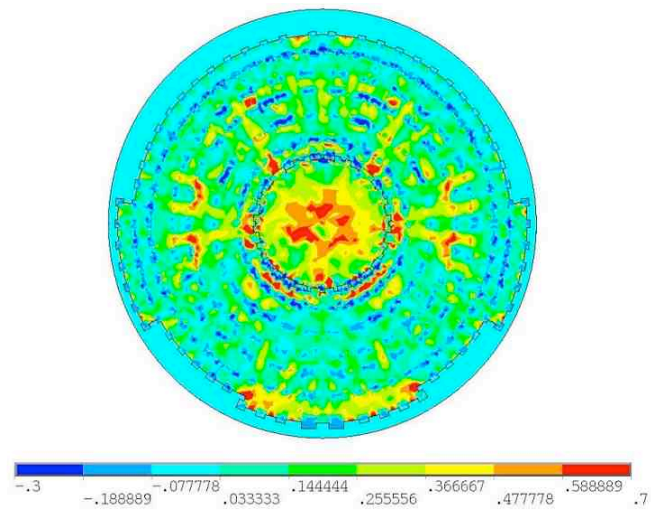

\subsection{Influence of underground water}

The design documents claim that dewatering measures should be taken when the underground water level is above $1 \mathrm{~m}$. The maximum water level during the underground water monitoring period is $4.15 \mathrm{~m}$, which is higher than the designed level. Therefore, in finite-element analysis, stress and deformation resulting from $1,2,3,4$, and $5 \mathrm{~m}$ water heads should all be considered.

Figs. 5 to 9 show the distribution of the first principal stress on the garage bottom floor at different water heads.

Fig. 4. Distribution of the first principal stress in the floor structure (unit: MPa)

Table 2. Extreme values of the underground garage floor parameters at different water heads

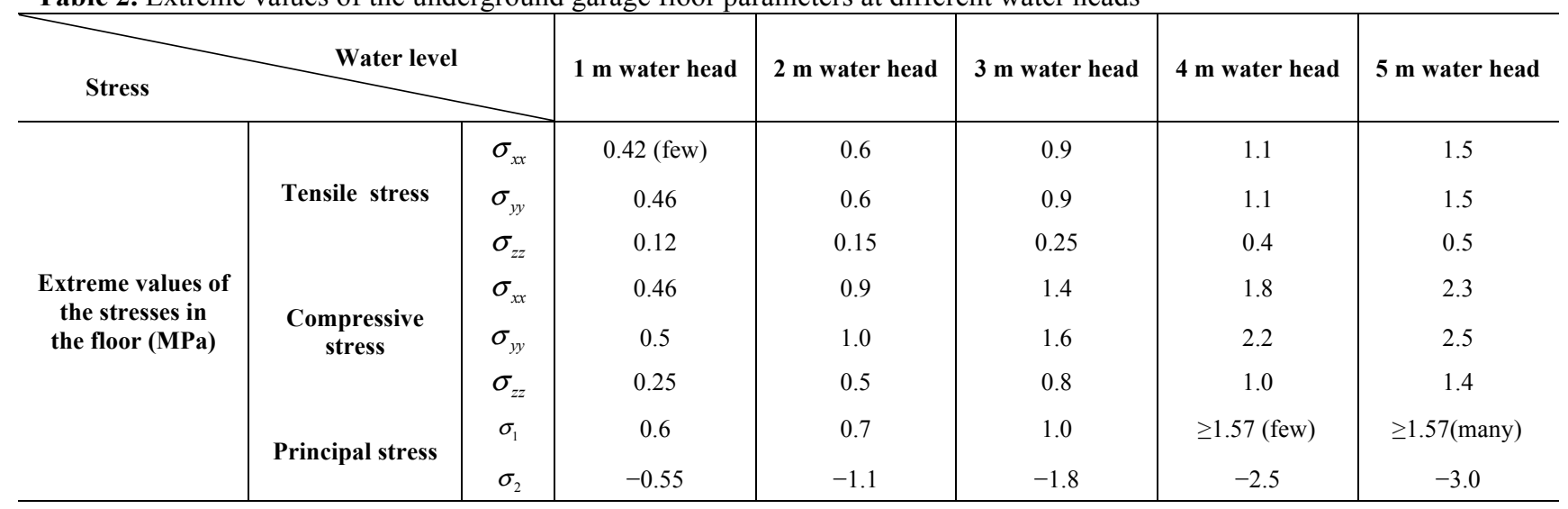

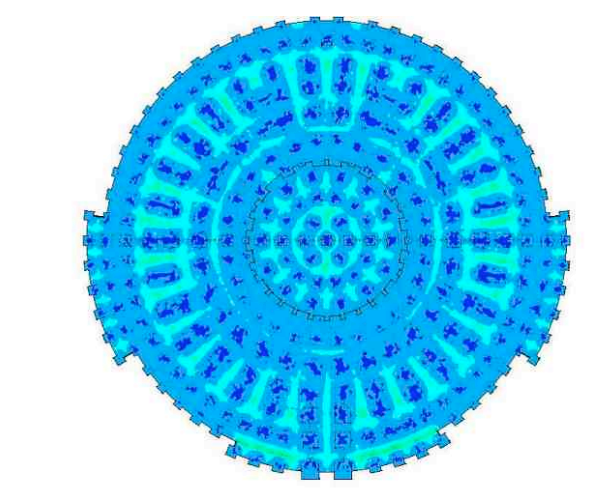

$\begin{array}{lllllll}-.2 & -.003333^{.193333} & .39 & .586667 & .793333^{.98} & 1.177^{1.373} & 1.57\end{array}$

Fig. 5. Distribution graph of the first principal stress in the bottom floor at a $1 \mathrm{~m}$ water head (unit: $\mathrm{MPa}$ )

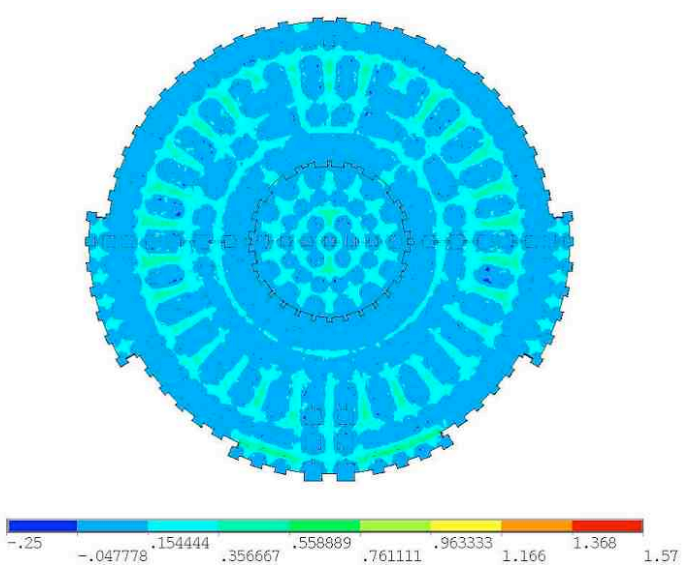

Fig. 6. Distribution graph of the first principal stress in the bottom floor at $2 \mathrm{~m}$ water head (unit: $\mathrm{MPa}$ )

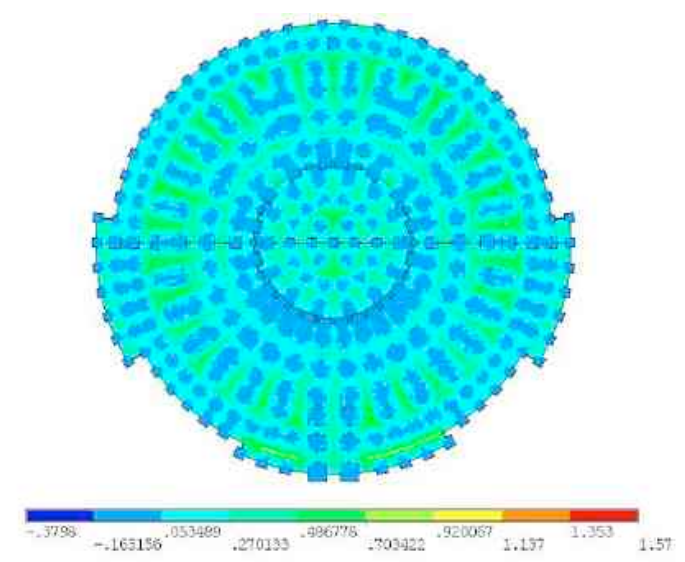

Fig. 7. Distribution graph of the first principal stress in the bottom floor at $3 \mathrm{~m}$ water head (unit: MPa)

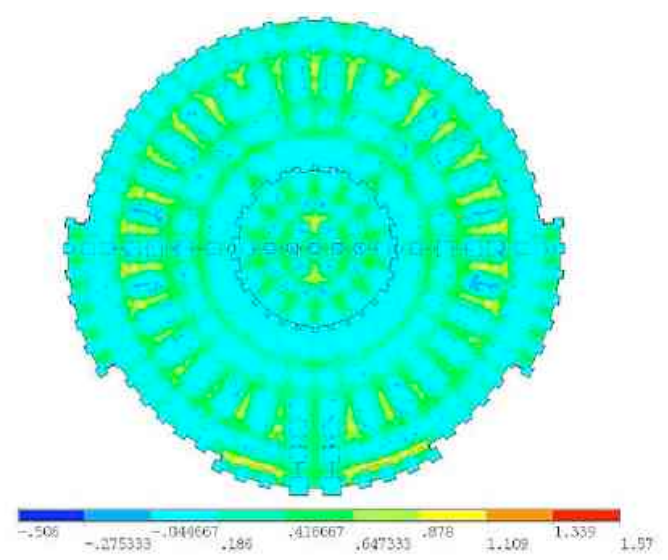

Fig. 8. Distribution graph of the first principal stress in the bottom floor at $4 \mathrm{~m}$ water head (unit: $\mathrm{MPa}$ ) 


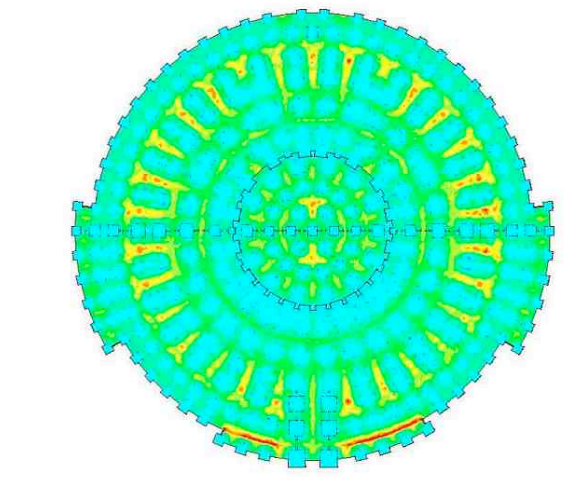

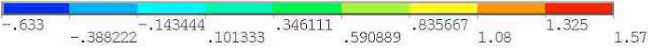

Fig. 9. Distribution graph of the first principal stress in the bottom floor at a $5 \mathrm{~m}$ water head (unit: $\mathrm{MPa}$ )

As the underground water level increases, the first principal stress in the bottom floor gradually increases and a higher principal stress covers more areas (Table 2 and Figs. 5 to 9). The maximum first principal stress mainly lies in the central part, which is located within a $44.6-57.8 \mathrm{~m}$ radius. When the water head becomes 1,2 , and 3 , the tensile stress and principal stress become lower than the tensile strength of the concrete. However, when the water head becomes $4 \mathrm{~m}$, the maximum value of the first principal stress in few parts of the floor exceeds $1.57 \mathrm{MPa}$, which is higher than the tensile strength of $\mathrm{C} 35$ concrete. Furthermore, when the water head becomes $5 \mathrm{~m}$, the maximum value of the first principal stress in many parts exceeds $1.57 \mathrm{MPa}$, particularly in the central part, which is located within a $44.6-57.8 \mathrm{~m}$ radius. These results are in accordance with the currently accepted cracking phenomenon.

At different underground water pressures, the maximum tensile stresses in the $X$ and $Y$ directions are mainly distributed in the central part, which is located within a $44.6-57.8 \mathrm{~m}$ radius.

\subsection{Influence of expansive soil}

Given that the bottom floor, foundation, and beam structure lie in a clay blanket, a change in the water content of clay can lead to soil expansion, which further causes stress deformation in floor-foundation interaction. Different soil thicknesses, expansion ratios, and Poisson ratios are considered in the calculation.

The extreme values of the first principal stresses under different engineering conditions are presented in Table 3.

Table 3. Extreme values of the first principal stresses under different engineering conditions

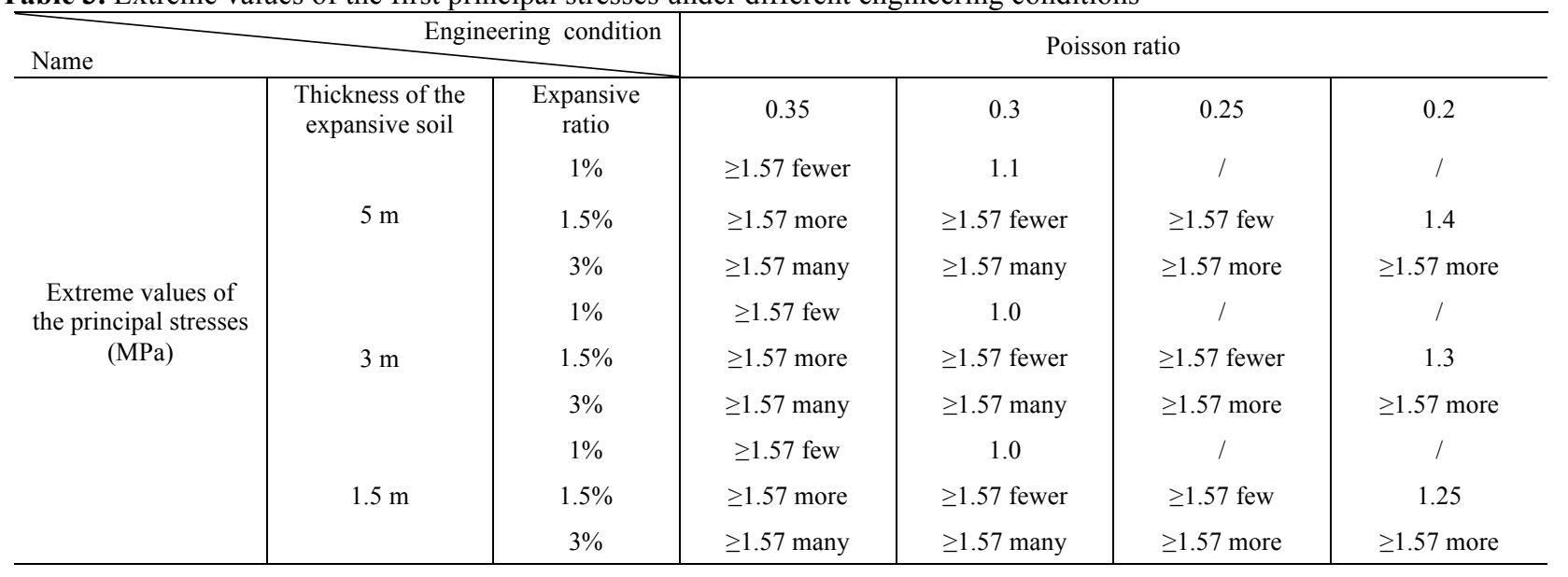

Figs. 10 to 15 show the distributions of the first principal stresses on the underground garage bottom floor at different

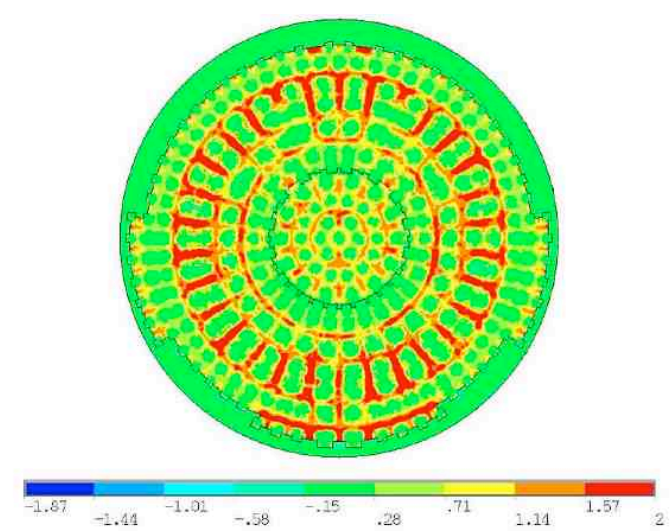

Fig. 10. Distribution graph of the first principal stress at 0.35 Poisson ratio and $1.5 \%$ expansive ratio (unit: MPa) expansion ratios and Poission ratios, with the thickness of the expansive soil set to $5 \mathrm{~m}$.

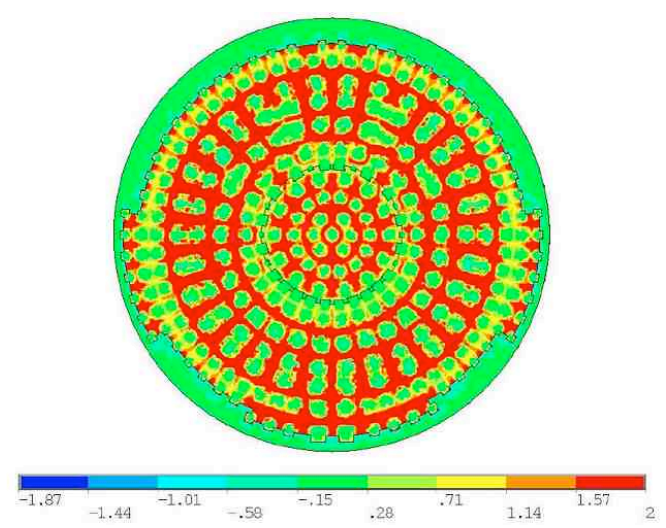

Fig. 11. Distribution graph of the first principal stress at 0.35 Poisson ratio and $3 \%$ expansive ratio (unit: $\mathrm{MPa}$ ) 


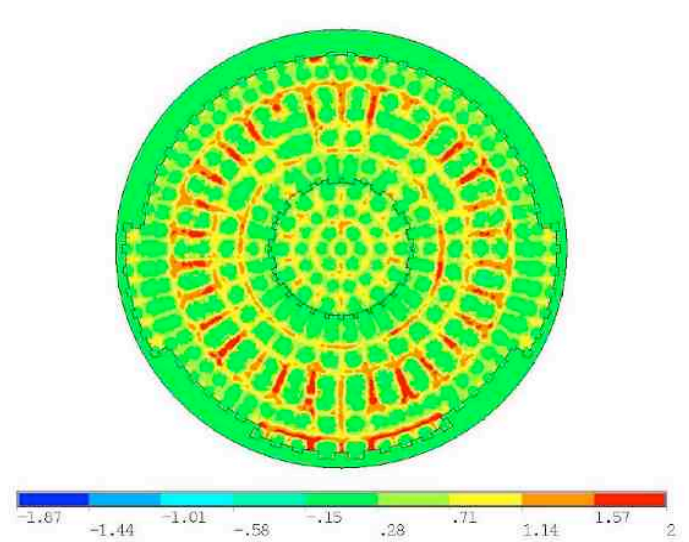

Fig. 12. Distribution graph of the first principal stress at 0.30 Poisson ratio and $1.5 \%$ expansive ratio (unit: $\mathrm{MPa}$ )

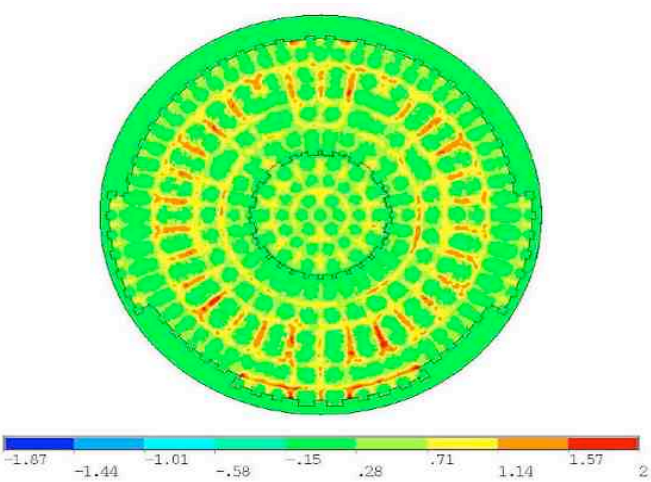

Fig. 14. Distribution graph of the first principal stress at 0.25 Poisson ratio and $1.5 \%$ expansive ratio (unit: $\mathrm{MPa}$ )

From Table 3 and Figs. 10 to 15 , the following can be deduced:

(1) As the soil expansion ratios and Poisson ratios increase, the first principal stress value in the bottom floor gradually increases and a higher principal stress covers more areas.

(2) As the thickness of expansive soil increases, the stress and displacement in the bottom floor steadily increases accordingly.

(3) At different expansion ratios, the maximum first principal stress is mainly distributed in the central part, which is located within a $44.6-57.8 \mathrm{~m}$ radius.

(4) At $1.5 \%$ expansion ratio, the maximum value of the first principal stress exceeds $1.57 \mathrm{MPa}$, which is the tensile strength of $\mathrm{C} 35$ concrete, in few parts of the bottom floor. At $3 \%$ expansion ratio, the maximum value of the first principal stress exceeds $1.57 \mathrm{MPa}$ in most areas (mainly around the central part of the bottom floor located within a 44.6-57.8 m radius).

\subsection{Influence of foundation settlement, water head pressure, and expansive soil}

According to the calculations and analyses, the water head pressure and soil expansion caused by the change in water content in the clay layer are possible reasons for the crack propagation in the underground garage floor. An increase in underground water level causes an increase in water head pressure, which consequently leads to an increase in the water content of the clay layer. These factors interact to produce a cracking effect. However, the effect of the foundation settlement and pressure loaded by the upper structure on the foundation soil is negligible.
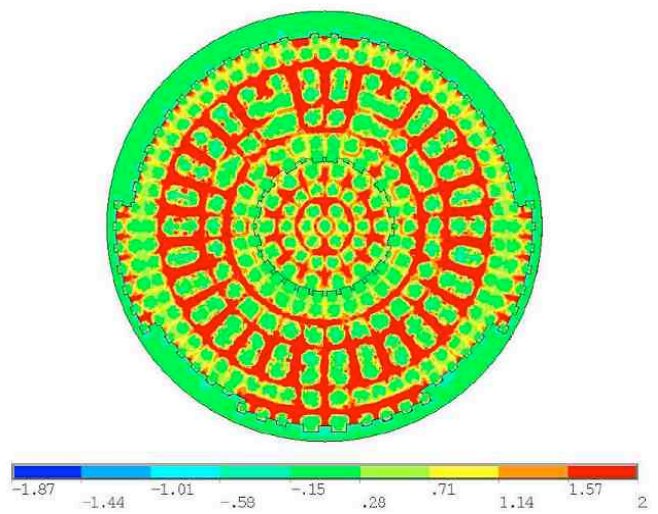

Fig. 13. Distribution graph of the first principal stress at 0.30 Poisson ratio and $3 \%$ expansive ratio (unit: $\mathrm{MPa}$ )

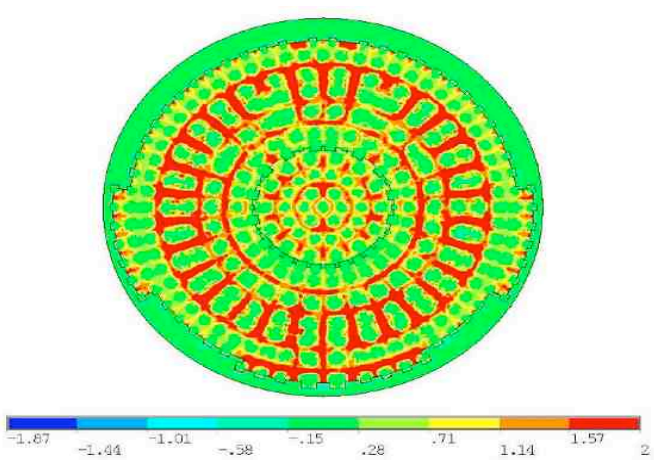

Fig. 15. Distribution graph of the first principal stress at 0.25 Poisson ratio and $3 \%$ expansive ratio (unit: $\mathrm{MPa}$ )

Therefore, factors such as the foundation settlement, water head pressure, and soil expansion caused by water content change in the clay blanket should be considered when studying the stress-strain changes in the underground garage floor and foundation of a skirt building. According to the numerical calculations, the upper structure load on the foundation top is converted to $150 \mathrm{kN} / \mathrm{m}^{2}$. The foundation floor is supposedly subjected to a $5 \mathrm{~m}$ water head pressure; at $1.5 \mathrm{~m}$ under the foundation floor, the volume ratio of the soil is supposed to be $1 \%$. The calculation results are shown through the distribution graph in Fig. 16. The results show

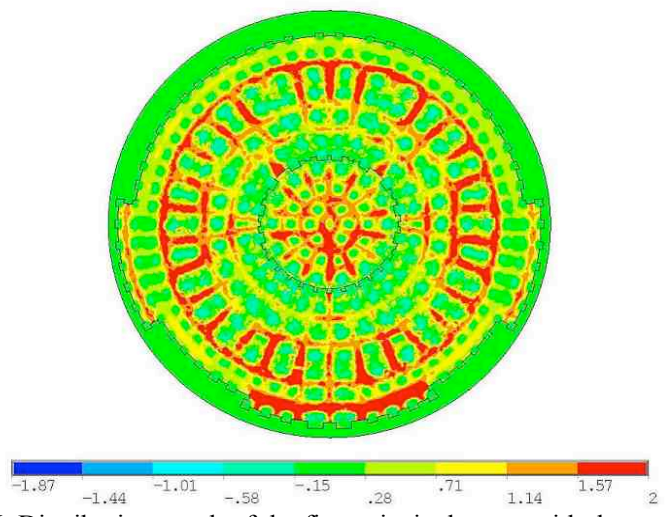

Fig. 16. Distribution graph of the first principal stress with the co-effect of foundation settlement, underground water pressure, and expansive soil ( $1 \%$ expansion ratio) (unit: MPa)

that the first principal stress exceeds $1.57 \mathrm{MPa}$ in many areas of the bottom floor, and these areas are mainly distributed in the central part, which is located within a $44.6-57.8 \mathrm{~m}$ radius. Cracks appear in many areas of the bottom floor, which is in accordance with the widely accepted cracking mechanism. 


\section{Discussion}

The maximum first principal stress in the bottom floor under the single influence of structural gravity when the foundation settles is approximately $0.6 \mathrm{MPa}$, which is lower than the tensile strength of the bottom floor concrete and most of the first principal stress values are within the range of $0.35-0.55 \mathrm{MPa}$. Under the single influence of underground water pressure, when the underground water head is lower than $3 \mathrm{~m}$, the maximum first principal stress is below the tensile strength of the bottom floor concrete. Thus, under the single influence of structural gravity or under a 3 $\mathrm{m}$ underground water head, the cracks caused by the foundation settlement are unlikely.

However, when the water head becomes $4 \mathrm{~m}$, the maximum value of the first principal stress in few parts of the bottom floor exceeds $1.57 \mathrm{MPa}$ or beyond the tensile strength of $\mathrm{C} 35$ concrete. Furthermore, when the water head becomes $5 \mathrm{~m}$, the maximum value of the first principal stress exceeds $1.57 \mathrm{MPa}$ in many parts of the bottom floor, particularly the central part, which is located within a 44.6 $57.8 \mathrm{~m}$ radius. At a $1.5 \%$ expansion ratio, the maximum value of the first principal stress exceeds $1.57 \mathrm{MPa}$ in few parts of the bottom floor. However, at a $3 \%$ expansion ratio, the maximum value of the first principal stress exceeds 1.57 $\mathrm{MPa}$, which is the tensile strength of $\mathrm{C} 35$ concrete, in most areas (mainly around the central part of the bottom floor within a $44.6-57.8 \mathrm{~m}$ radius).

Once the principal stresses at the integration points reach a 1.57 MPa tensile strength, concrete cracking will probably occur. Thus, when the water head exceeds $4 \mathrm{~m}$ or the soil expansion ratio reaches $1.5 \%$, cracks will appear mainly around the central part of the bottom floor with a radius between 44.6 and $57.8 \mathrm{~m}$. These results are in accordance with the widely accepted cracking phenomenon. Underground water not only exerts a pushing force from the bottom but also causes the expansibility of expansive soil. According to field detection, calculation, and underground water-level monitoring, underground water causes bottom floor cracks.

\section{Conclusions}

Ensuring the engineering quality of an underground garage is a complicated and practical problem. By conducting practical project monitoring, along with site detection, a finite-element model is established and adopted to study the mechanical properties of the bottom floor-foundation and beam-soil system. The changes in stress under the influence of various factors such as foundation settlement, underground water level, soil expansion caused by water content, and Poisson ratio are studied to explore the causes of cracks in the bottom floor of a garage. On the basis of calculation and analysis, the following conclusions have been drawn:

(1) The influence of underground water on underground garage structures. Considering that large underground projects last long in terms of engineering duration and cover both the pluvial period and brief rain period, in which underground water level considerably changes, dewatering treatment has a significant effect on the quality of underground garage projects.

(2) The influence of expansive soil on underground garage structures. Owing to the infiltration of the surface water, the clay foundation expands to produce a vertical pushing force, which induces cracking. Thus, engineering designers and contractors should practice great caution in designing underground garage structure systems.

(3) During deuteric operating periods, the underground water level of the basement should be controlled to prevent the bottom floor from cracking.

\section{Acknowledgements}

This research was funded by key project of natural science research of Anhui higher education (KJ2015A151), the talent research fund project of Hefei University and project of Hefei University key disciplines construction of civil engineering (2014xk04)

\section{References}

1. Wu Lijian, Zhong Falin, "Simulation of Bond-slip Relationship Between Concrete And Reinforcing Bar in ANSYS ", Journal of Tiajin in University, 39(2), 2006, pp. 209-213.

2. HE Shukai, WANG Laigui, "Realization of RC Structure Dehiscence Analysis with ANSYS ", Journal of Liaoning Technical University, 26(11), 2007, pp. 125-127.

3. XU Hangtian, SHAN Shujun, "Effect of Viscous Damping in a Soft Stiffness Shock Isolation System", Journal of Vibration and Shock, 29(2), 2010, pp. 199-202.

4. XU Mingbiao, PENG Dehong, "Blasting Vibration Tests And Ansys Time-history Analyses of Slope Responses", Chinese Journal of RockMechauics and Eugiueeriug, 31(5), 2012, pp. 26302635.

5. LI Yongqiang, HUAN Qiang, Wu Changxing, "Dynamic Response of Honeycomb Sandwich Panel Under Impact Loading Based on Ansys", Journal of Northeastern University(Natural Science), 36(6), 2015, pp. 858 862.

6. Wu, Xun, et al. "The Crack Resistance Analysis in Mid-Span Closure Segment of Continuous Rigid-Frame Box Girder Bridge Based on ANSYS". Intelligent Computation Technology and Automation (ICICTA), 2014 7th International Conference on IEEE, 2014: 987-990.

7. Li Xuehong, Ye Yanhua. "Approach of rough set to extracting cause of crack hydraulic concrete structure." Journal of Southeast University, 36 (11), 2006, pp. 145-149.
8. XUE Jingjing, "Static Cause Analysis of Floor Cracks for Powerhouse of Hydropower Station with 3D Finite Element Method", Water Resources and Power, 2(2), 2011, pp. 72-75.

9. Chen, Zong Ping, et al. "Theoretical calculation and cause analysis of the cracking of concrete foundation ring wall of liquid tanks." Journal of Guangxi University, 37(1), 2012, pp.14-20.

10. Cao G D, Chen S C, et al, "Study on Crack Causes of Arch Dam by Using 3D Finite Element Analysis", Yellow River, 35(7), 2013, pp. $110-113$.

11. ZHANG Xiaodong, DING Yong, et al, "Simulation of the Concrete Crack Propagation Process with the Extended Finite Element Method", Engineering Mechanics, 30(7), 2013, pp. 14-21.

12. Chen, Qin, et al. "Analysis on Cracking Cause and Propagation Trend of Concrete Dam." Applied Mechanics \& Materials, 444-445, 2014, pp.831-835.

13. Slowik, Volker, and Victor E Saouma. "Water Pressure in Propagating Concrete Cracks." Journal of Structural Engineering, 126(2), 2014, pp.235-242.

14. ZHAO Weiping, GONG Hang, et al, "Prediction on Crack Width based on ANSYS Nonlinear Analysis", International Conference on Mechanics and Civil Engineering, 2014, pp.433-435.

15. Fialko S. "Quadrilateral Finite Element for Analysis of Reinforced Concrete Floor Slabs and Foundation Plates". Applied Mechanics \& Materials, 725-726(6), 2015, pp. 820-835. 